\title{
POTENCIAL DE PRODUÇÃO DE ÓLEO-RESINA DE COPAÍBA (Copaifera spp) DE POPULAÇÕES NATURAIS DO SUDOESTE DA AMAZÔNIA ${ }^{1}$
}

Onofra Cleuza Rigamonte-Azevedo², Paulo Guilherme Salvador Wadt ${ }^{3}$ e Lúcia Helena de Oliveira Wadt ${ }^{4}$

\begin{abstract}
RESUMO - O potencial de produção de óleo-resina extraído de Copaífera spp foi avaliado em duas populações naturais do sudoeste da Amazônia brasileira (municípios de Tarauacá e Xapuri), nos anos de 2000 e 2001. Foram selecionadas 388 árvores adultas de copaíbas das duas populações, sendo identificados em cada árvore o diâmetro à altura do peito (DAP), a produção de óleo-resina, a posição da árvore no relevo local (baixio ou terra firme) e a tipologia florestal local (floresta aberta ou densa), além do nome regional da copaíba, com base em características morfológicas da casca: Copaifera reticulata: copaíba-branca, vermelha, amarela e preta e Copaifera paupera: mari-mari. Os resultados indicam que a copaíba mari-mari possui maior proporção de indivíduos produtivos (80\%), enquanto os demais morfotipos apresentaram apenas de 22 a $40 \%$ de seus indivíduos produtivos. Com relação a todas as árvores amostradas, a produção de óleo-resina variou de 0 a $18 \mathrm{~L}$ árvore $^{-1}$, com a copaíba mari-mari tendo a maior produção média (1,33 L árvore $\left.{ }^{-1}\right)$, porém sem diferir significativamente dos demais morfotipos. Após excluir da análise as árvores não produtivas, a copaíba-preta apresentou significativamente a maior produção média de óleo-resina (2,92 L árvore $\left.{ }^{-1}\right)$. A tipologia florestal, posição da árvore no relevo e o DAP não se mostraram relacionados a produção de óleo-resina.
\end{abstract}

Palavras-chave: Copaifera, produção de óleo resina e Amazônia.

\section{OIL RESIN PRODUCTION POTENTIAL OF Copaifera spp NATURAL POPULATIONS IN THE SOUTHWESTERN BRAZILIAN AMAZON}

\begin{abstract}
The potential for production of oil resin extracted from Copaifera spp natural populations was studied in two natural populations (municipalities of Tarauacá and Xapuri) in the Southwestern Brazilian Amazon, in 2000 and 2001. Three hundred and eighty-eight adult trees were selected within these two populations. DBH, oil production, topographic position, regional common names (based on bark appearance; White, Red, Yellow, Black for Copaifera reticulata, and Mari-Mari for C. paupera) and forest typology were recorded for each individual. Copaiba Mari-Mari had the highest proportion of oil-producing individuals (80\%), whereas the other types varied between $22-40 \%$. Within the studied population, oil production varied between 0 and 18 liters.tre $e^{-1}$, with Copaiba Mari-Mari having average oil production of 1.33 liters.tre ${ }^{-1}$, not being significantly different from the other types. After excluding non-productive trees, Black Copaiba had the highest average oil production (2.92 liters.tre $\left.{ }^{-1}\right)$. Forest type, diameter and topography were not significantly related to oil production.
\end{abstract}

Keywords: Copaifera, Southwestern Brazilian Amazon, population structure and oil resin production.

\footnotetext{
${ }^{1}$ Recebido em 10.12.2004 e aceito para publicação em 05.04.2006.

${ }^{2}$ SOS Amazonas. R. Pará, 61. Cadeira Velha, 69900-440 Rio Branco, AC.

${ }^{3}$ Empresa Brasileira de Pesquisa Agropecuária, Centro de Pesquisa Agroflorestal do Acre, Rod. BR 364, km 14, Caixa Postal 321,69908-970, Rio Branco, AC. E-mail:<paulo@cpafac.embrapa.br>.

${ }^{4}$ Empresa Brasileira de Pesquisa Agropecuária, Centro de Pesquisa Agroflorestal do Acre, Rod. BR 364, km 14, Caixa Postal 321, 69908-970, Rio Branco, AC. E-mail: <lucia@cpafac.embrapa.br>.
} 


\section{INTRODUÇÃO}

A importância das árvores de copaíba (Copaífera spp.) deve-se à sua madeira de boa qualidade e à produção de óleo-resina, este utilizado pelas populações tradicionais e indústrias farmacêuticas devido às suas propriedades terapêuticas. O óleo-resina da copaíba pode ser usado puro ("in natura" ou destilado), ou como componente na preparação de uma variedade de produtos terapêuticos e cosméticos, como xaropes, pomadas, cápsulas, óvulos vaginais, cremes, sabonetes, xampus, detergentes e loções; possui ainda potencial para uso industrial em tintas, vernizes e como fixador de fragrância de perfumes (SEBRAE, 1995; SAMPAIO, 2000).

Em face das diversas pressões antrópicas atuantes sobre os ecossistemas amazônicos, a exploração do óleo-resina da copaíba, por meio de manejo florestal, pode constituir-se numa importante atividade para a conservação das florestas e manutenção da tradição extrativista das populações locais. No entanto, para que essa estratégia seja viável, é necessário conhecer melhor a dinâmica dessa espécie, visando subsidiar seu manejo. Dentre os fatores de manejo que podem ser considerados, estão o potencial produtivo dos diferentes morfotipos de copaíba encontrados na região e os fatores ambientais que influenciam a produção do óleo-resina.

No bioma amazônico ocorrem várias espécies do gênero Copaifera, entretanto, normalmente sua identificação botânica não é feita de forma sistemática (VEIGA Jr. e PINTO, 2002), o que tem limitado a identificação no nível de gênero ou no conhecimento empírico das características morfológicas da casca e das folhas (FERREIRA, 1999; LEITE et al., 2001; PLOWDEN, 2001; 2003).

No Estado do Acre são reconhecidos seis "morfotipos" de copaíbeiras, cuja classificação é baseada nas características morfológicas da casca e das folhas: copaíba-preta da placa grande, copaíba-preta da placa pequena, copaíba-branca, copaíba-amarela, copaíbavermelha e copaíba-mari-mari (LEITE et al., 2001). Neste estudo, não se faz distinção entre a copaíba-preta da casca grande e a copaíba preta da casca pequena, sendo ambas consideradas um único morfotipo.

A produção de óleo-resina por árvore é muito variável, e ainda não se tem conhecimento sobre os fatores que a determinam. As condições ambientais dos locais de crescimento das árvores, a época do ano e suas características genéticas são tidas como responsáveis por parte da variação observada na produção das árvores (ALENCAR, 1982). Alguns estudos avaliaram o efeito de características físicas do solo, tamanho da árvore (DAP) e época do ano sobre a produção da copaíba (PLOWDEN, 2003; ALENCAR, 1982; LEITE et al., 2001; FERREIRA, 1999), porém não há ainda nenhuma conclusão definitiva.

Avaliações realizadas no início do século passado indicam diferenças na produção entre as diversas espécies de copaíba (PIO CORRÊA, 1931), sendo C. reticulata a espécie considerada de maior potencial produtivo, em comparação com C. martii Hayne. Atualmente, considera-se que a produção média varia de 0,3 a 3 Lárvore $^{-1}$, podendo ser esperado ocasionalmente indivíduos com produção da ordem de $30 \mathrm{~L}^{2}$ arvore ${ }^{-1}$ para uma coleta, sem haver informações, entretanto, do tempo para que novas coletas possam ser refeitas em uma mesma árvore.

Além da produção por árvore, outro fator que afeta a produção é a proporção de árvores produtivas na área explorada. Na Reserva Ducke, em Manaus, AM, Alencar (1982) observou em C. multijuga uma proporção de $24 \%$ de árvores produtivas em solos arenosos e de 39\% em solos argilosos. Ferreira (1999), avaliando a produção de óleo-resina de copaíba na Floresta Estadual do Antimary, no sudeste do Estado do Acre, observaram que a proporção de árvores produtivas foi de $72 \%$ no período seco e de apenas $41 \%$ na estação chuvosa. Este último resultado é contraditório com o relatado por Baima et al. (1999), na região do Tapajós, PA, onde foi observado que na estação seca a produção de óleo-resina seria menor. Por sua vez, Plowden (2003) encontrou uma proporção de $61 \%$ de copaíbas produtivas em uma reserva indígena do Pará, enquanto no Estado do Acre se estima que apenas $25 \%$ das árvores adultas sejam produtivas (LEITE et al., 2001).

As estimativas de produção podem variar ainda em relação ao tipo de manejo para a retirada do óleo e do período entre extrações consecutivas. A re-extração em uma mesma árvore também deve ser considerada quando se planeja produzir óleo-resina de copaíba. Extrações realizadas em intervalos semestrais apresentaram resultados variáveis, em que na maioria das vezes as quantidades de óleo-resina extraído foram 
maiores na segunda extração, ocorrendo declínio da produção na terceira coleta. Em alguns casos, só foi possível extrair óleo-resina na primeira coleta (ALENCAR, 1982).

Nesse sentido, o objetivo deste trabalho foi avaliar a produção de cinco morfotipos de copaibeiras, como também sua relação com o diâmetro da árvore e com o local de crescimento da árvore (tipo de floresta e ambiente edáfico), nas condições edafoclimáticas do sudoeste da Amazônia brasileira.

\section{MATERIAL E MÉTODOS}

A avaliação de produção da copaíba foi realizada em dois municípios do Estado do Acre: Tarauacá (Vale do Rio Juruá) e Xapuri (Vale do Rio Acre). No Município de Xapuri, o local de estudo foi o Seringal Floresta, na Reserva Extrativista Chico Mendes, localizado a aproximadamente $20 \mathrm{~km}$ ao Norte da cidade de Xapuri (10 30' 37' S e 68 33' 46" W). A tipologia predominante nessa região é a Floresta Ombrófila Aberta, com clima do tipo equatorial quente e úmido, caracterizado por temperatura média anual de $25^{\circ} \mathrm{C}$ e pluviosidade média anual de $1.930 \mathrm{~mm}$ e alta umidade relativa do ar (ACRE, 2000).

No Município de Tarauacá, o local de estudo foi o Seringal União, localizado às margens do rio Tarauacá, cerca de $80 \mathrm{~km}$ a leste da cidade de Tarauacá $\left(08^{\circ} 30^{\prime}\right.$ $\left.4,7^{\prime \prime} \mathrm{S} \mathrm{e} 71^{\circ} 25^{\prime} 11,4^{\prime \prime} \mathrm{W}\right)$. A tipologia florestal predominante nessa região é a Floresta Ombrófila Aberta com clima do tipo equatorial quente e úmido, com temperatura média anual de $24,4{ }^{\circ} \mathrm{C}$ e pluviosidade média anual de $2.244 \mathrm{~mm}$ (ACRE, 2000).

Para a estimativa da produção de óleo-resina, foram utilizadas em cada seringal árvores de copaibeiras, aparentemente sadias com diâmetro à altura do peito (DAP) maior que $35 \mathrm{~cm}$, previamente selecionadas em plano de manejo extrativista.

No seringal Floresta, foram avaliadas 273 árvores e no seringal União, 115 árvores, totalizando 388 exemplares. Em cada árvore amostrada, mediu-se a circunferência à altura do peito (CAP) com fita métrica, sendo os resultados transformados em DAP; identificouse o morfotipo de copaíba sob a orientação de um identificador botânico prático.

Todas as coletas foram realizadas na estação chuvosa, nos meses de janeiro e fevereiro de 2001 (seringal
União) e janeiro a fevereiro de 2002 (seringal Floresta). Para a coleta do óleo-resina, utilizou-se trado com diâmetro de $1,9 \mathrm{~cm}$ e comprimento suficiente para atingir o centro do tronco das árvores amostradas, fazendo dois furos perpendiculares entre si e à altura de 1,30 m do solo em cada árvore. Após a perfuração, o óleo exsudado foi recolhido por meio de um cano de PVC embutido em uma mangueira até o recipiente coletor, conforme técnica utilizada por outros autores (ALENCAR, 1982; LEITE et al., 2001; FERREIRA, 1999). As árvores amostradas foram classificadas em produtivas e nãoprodutivas. Árvores que no momento da perfuração apresentaram serragem oleosa, mas não chegou a escorrer óleo-resina, foram consideradas não-produtivas.

No seringal União, o óleo-resina foi coletado durante o período de 24 horas, após a qual se lacrou o furo. No seringal Floresta, o furo não foi fechado, e a extração prosseguiu até a completa exaustão do óleo-resina, anotando-se os volumes coletados no período de 24 horas e no período compreendido pela completa exaustão. Somente após a coleta do óleo-resina, o furo foi tapado para evitar a entrada de fungos e insetos que pudessem causar doenças na árvore.

Quanto às características do ambiente em torno do local de crescimento de cada árvore, ele foi classificado quanto à cobertura florestal ("Floresta Aberta" e "Floresta Densa") e quanto à natureza do ambiente edáfico ("Baixio" e "Terra Firme"). "Floresta Aberta" foi considerado quando o dossel era aberto, com a presença de indivíduos arbóreos bem esparsos e sub-bosque denso. "Floresta Densa" representou dossel fechado e presença de grandes árvores que emergem de um estrato arbóreo uniforme, de 25 a $35 \mathrm{~m}$ de altura e com bosque e sub-bosque de baixa luminosidade e pouca vegetação.

Ambiente de "Baixio" foram consideradas as áreas côncavas ou planas que ocupavam cotas mais baixas na paisagem, normalmente com sinais de drenagem deficiente ou sujeitas a alagamentos periódicos. Ambientes de "Terra Firme" foram consideradas todas as áreas convexas ou planas, com aparência de boa drenagem.

Os dados de produção foram analisados por meio de análise de variância (ANOVA), teste de médias de Tukey e teste $t$ para contraste da produção em cada um dos morfotipos em relação aos demais. Foram feitas, ainda, comparações pelo teste $t$, independente do

R. Árvore, Viçosa-MG, v.30, n.4, p.583-591, 2006 
morfotipo, das médias de produção entre a tipologia florestal e o ambiente edáfico de entorno de cada árvore amostrada. O relacionamento entre o DAP e a produção foi determinado por meio de análise de regressão polinomial de grau 2. Foi também utilizado o teste $\mathrm{t}$ para comparar a produção obtida por um período de 24 horas em relação à produção obtida até a exaustão completa do óleo-resina.

A freqüência de morfotipos, árvores produtivas, árvores não-produtivas e árvores ocadas de copaíba, nos seringais Floresta e União, foi avaliada por meio do teste de $\chi 2$.

\section{RESULTADOS E DISCUSSÃO}

As 388 copaibeiras amostradas foram classificadas como pertencentes a cinco diferentes morfotipos de copaíba: amarela, branca, mari-mari, preta e vermelha. A identificação botânica desses cinco morfotipos indicaram que os morfotipos copaíba-amarela, branca, preta e vermelha correspondem a Copaifera reticulata Duke, enquanto o morfotipo mari-mari, embora ainda não tendo a identificação botânica definitiva, corresponde à Copaifera cf paupera. Os exemplares de copaíbasamarela, branca, preta e vermelha distinguem-se entre si por meio de características morfológicas das cascas, identificadas empiricamente por identificadores botânicos práticos e seringueiros, representando variações dentro da mesma espécie. Essas diferenças morfológicas podem ser atribuídas à grande variabilidade genética da espécie, sendo necessários estudos mais conclusivos sobre sua identificação botânica.

Em Tarauacá, 43\% das árvores foram classificadas como copaíba-vermelha, enquanto em Xapuri $77 \%$ foram identificadas como copaíba-preta, não tendo sido registrado nesse local nenhuma copaíba-mari-mari (Quadro 1). A diferente proporção de morfotipos de copaíba entre os dois locais (Tarauacá e Xapuri) indica grande variabilidade entre os ecossistemas amazônicos indicando a necessidade de estudos botânicos e a elaboração de guias de identificação das espécies, como forma de subsidiar a avaliação do potencial de manejo dessa espécie.

Quadro 1 - Freqüência de morfotipos, árvores produtivas, árvores não-produtivas e árvores ocadas de copaíba, nos seringais Floresta e União

Table 1 - Frequency distribution of morphotypes, producing adults, non-producing adults and hollow trees of copaiba in two extractive reserves (Floresta and União)

\begin{tabular}{|c|c|c|c|c|c|c|c|c|}
\hline \multirow[t]{2}{*}{ Seringal } & \multirow{2}{*}{$\begin{array}{l}\text { Contagens } \\
\text { de Árvores }\end{array}$} & \multirow[t]{2}{*}{ Árvores } & \multicolumn{6}{|c|}{ Morfotipos de copaíba } \\
\hline & & & Amarela & Branca & Mari-mari & Preta & Vermelha & Total \\
\hline \multirow{8}{*}{$\begin{array}{l}\text { União } \\
\text { (Tarauacá) }\end{array}$} & Produtivas $^{* *}$ & & 5 & 4 & 22 & 4 & 11 & 46 \\
\hline & & & $(38,5 \%)$ & $(30,8 \%)$ & $(81,5 \%)$ & $(33,3 \%)$ & $(22,0 \%)$ & $(40,0 \%)$ \\
\hline & Não- & Ocadas & 2 & 0 & 2 & 1 & 6 & 11 \\
\hline & produtivas & & $(15,4 \%)$ & $(0 \%)$ & $(7,4 \%)$ & $(8,3 \%)$ & $(12,0 \%)$ & $(9,6 \%)$ \\
\hline & & Não & 6 & 9 & 3 & 7 & 33 & 58 \\
\hline & & ocadas & $(46,2 \%)$ & $(69,2 \%)$ & $(11,1 \%)$ & $(58,3 \%)$ & $(66 \%)$ & $(50,4 \%)$ \\
\hline & Amostradas & & 13 & 13 & 27 & 12 & 50 & 115 \\
\hline & & & $(100 \%)$ & $(100 \%)$ & $(100 \%)$ & $(100 \%)$ & $(100 \%)$ & $(100 \%)$ \\
\hline \multirow{9}{*}{$\begin{array}{l}\text { Floresta } \\
\text { (Xapuri) }\end{array}$} & Produtivas $^{\text {ns }}$ & & 4 & 5 & & 62 & 8 & 79 \\
\hline & & & $(23,5 \%)$ & $(29,4 \%)$ & & $(29,4 \%)$ & $(28,6 \%)$ & $(28,9 \%)$ \\
\hline & Não- & Ocadas & 1 & 1 & & 28 & 5 & 35 \\
\hline & produtivas & & $(5,9 \%)$ & $(5,9 \%)$ & & $(13,3 \%)$ & $(17,9 \%)$ & $(12,8 \%)$ \\
\hline & & Não & 12 & 11 & & 121 & 15 & 159 \\
\hline & & ocadas & $(70,5 \%)$ & $(64,7 \%)$ & & $(57,3 \%)$ & $(53,5 \%)$ & $(58,2 \%)$ \\
\hline & Amostradas & & 17 & 17 & & 211 & 28 & 273 \\
\hline & & & $(100 \%)$ & $(100 \%)$ & & $(100 \%)$ & $(100 \%)$ & $(100 \%)$ \\
\hline & Total & & 30 & 30 & 27 & 223 & 78 & 388 \\
\hline
\end{tabular}

** Significativo a $1 \%$, por meio do teste qui-quadrado; ${ }^{\text {ns }}$ não-significativo pelo teste qui-quadrado.

Árvores produtivas, não-produtivas e ocadas.

R. Árvore, Viçosa-MG, v.30, n.4, p.583-591, 2006 
Leite et al. (2001) consideraram que no Estado do Acre $25 \%$ das copaibeiras são produtivas. Neste estudo, a proporção de árvores produtivas em Xapuri foi de $28,9 \%$, variando de $23,5 \%$ na copaíba-amarela a $29,4 \%$ na branca e preta, não havendo diferença significativa pelo teste de $\chi 2(p<0,1)$, nas respectivas proporções entre os morfotipos avaliados (Quadro 1). Contudo, em Tarauacá, a média de árvores produtivas foi de $40 \%$, diferença essa explicada pela maior proporção de árvores produtivas de copaíba-mari-mari, cuja proporção foi de $81 \%$ (Quadro 4.1). Excluindo-se as árvores de copaíba-mari-mari, a proporção de árvores produtivas foi de $27 \%$.

As diferenças observadas na proporção de árvores produtivas não têm sido explicadas pela literatura, embora esse seja um componente do potencial produtivo de determinada área a ser manejada e haja relatos de diferenças em relação a determinadas condições ambientais. Um fator importante a ser considerado quando se trata da proporção de árvores não-produtivas é a ocorrência de árvores ocadas. Neste estudo, considerando todos os morfotipos de copaíba, a proporção de árvores ocadas em Tarauacá variou de 0 a 15,4\% e em Xapuri, de 5,9 a 17,9\%. Entretanto, a análise estatística desses dados pelo teste de qui-quadrado ficou prejudicada em função do pequeno número de casos de árvores ocadas, e assim não foi considerada (Quadro 1).

Além da proporção de árvores produtivas e de sua condição física (ocada ou não), outro fator determinante da capacidade de produção de uma área é a produção das árvores, a qual varia grandemente de uma árvore para outra. Ainda, além da capacidade produtiva da árvore per si, o tempo de coleta pode afetar a estimativa da produção de óleo-resina por árvore. Geralmente, os estudos sobre produção da copaíba não fazem referência ao tempo de coleta do óleo-resina (FERREIRA, 1999; PLOWDEN, 2003;ALENCAR, 1982), embora Leite et al. (2001) proponham que a coleta seja feita até a completa exaustão.

Nas coletas realizadas em Xapuri, comparou-se a produção obtida em 24 horas (Prod24h), com a produção a até completa exaustão (ProdTot). Entretanto, a média de produção entre os dois tempos de coleta foi estatisticamente iguais ( $t, p=0,28)$. Este resultado pode ser explicado pelo fato de que em muitas árvores a exudação do óleo-resina encerrou-se naturalmente antes das primeiras 24 horas de coleta, indicando que esse período pode ser utilizado em outros estudos.
É importante ainda relatar que não há, até o momento, nenhuma indicação segura de que a exaustão do óleoresina durante a coleta não cause danos fisiológicos ou comprometa a viabilidade da árvore, de forma que, pelo fato de a produção ter sido estatisticamente igual entre os dois períodos, sugere-se que esse tempo de coleta seja adotado até que estudos mais conclusivos sejam realizados.

A produção de óleo-resina nas árvores amostradas foi variável, com amplitudes de 0 e 18,0 L árvore ${ }^{-1}$, com média de 0,94 L árvore ${ }^{-1}$ (Quadro 2). Considerando todas as árvores amostradas, a produção média variou de 0,38 Lárvore ${ }^{-1}$ de copaíba-vermelha até 1,33 Lárvore ${ }^{-1}$ de copaíbamari-mari. A maior média de produção de copaíba-marimari explica-se pelo fato de esse morfotipo ter apresentado elevada proporção de árvores produtivas (Quadro 1). Entretanto, as médias de produção entre os morfotipos de copaíba, no total de árvores amostradas, não diferiram entre si pela análise de variância (Quadro 3).

Analisando-se apenas as árvores efetivamente produtivas (excluindo-se as árvores não-produtivas), a produção média foi de 2,92 Lárvore ${ }^{-1}$, e neste caso a produção média variou de 1,57 L árvore ${ }^{-1}$ para a copaíba vermelha a até 3,84 $\mathrm{L}$ árvore $^{-1}$ para a copaíba preta (Quadro 2). A análise de variância indicou haver diferença entre as médias de produção dos cinco morfotipos avaliados (Quadro 3), contudo o teste de médias de Tukey não indicou nenhuma diferença entre as médias $(\mathrm{p}<0,05)$. Em qualquer uma das situações (total de árvores amostradas ou apenas árvores produtivas), não houve efeito do município, embora a interação município $\mathrm{x}$ morfotipo tenha sido significativa (Quadro 3). Ressaltase, entretanto, que a copaíba-mari-mari ocorreu em apenas um município, o que por si só já afeta a interação entre o morfotipo e o local (município).

Por este motivo, utilizou-se o teste de contrastes para comparar a média de produção de cada morfotipo com a média de produção dos demais morfotipos (teste $\mathrm{t}, \mathrm{p}<0,05$ ) (Quadro 4). Esses resultados indicam que somente a copaíba-preta apresentou uma produção de óleo-resina superior à apresentada pelos demais morfotipos.

Embora a produção média de óleo-resina tenha sido dependente do morfotipo de copaíba, esta foi, no entanto independente do ambiente (baixo e terra firme), do tipo de floresta (aberta e densa) e do local de estudo (seringais e municípios), tanto nas árvores

R. Árvore, Viçosa-MG, v.30, n.4, p.583-591, 2006 
amostradas quanto apenas naquelas produtivas (Quadro 5), resultados esses diferentes daqueles relatados na literatura. Ferreira (1999), por exemplo, concluíram que as condições ambientais afetaram a produção média de óleo-resina, a qual teria sido maior em terra firme $\left(1,7 \mathrm{~L}\right.$ árvore $\left.^{-1}\right)$ que em várzea $\left(0,14 \mathrm{~L}_{\text {árvore }}{ }^{-1}\right)$. Estudos realizados no Amazonas com Copaifera multijuga também indicaram haver dependência entre a textura do solo (arenosa ou argilosa) e a produtividade de óleo-resina, em que a produção foi maior nos solos argilosos $\left(0,23 \mathrm{~L}^{2}\right.$ ávore $\left.^{-1}\right)$ que naqueles arenosos $(0,16$ L árvore $^{-1}$ ) (ALENCAR, 1982).

Os valores do diâmetro à altura do peito (DAP) para as árvores de copaíba variaram de 36 a 180 cm, considerando as 388 árvores amostradas. Em função desta distribuição, foram definidas 15 classes de diâmetro, cada uma com incrementos de $10 \mathrm{~cm}$ (Quadro 6).

Quadro 2 - Produção (24 horas), em litros, de óleo-resina por diferentes morfotipos de copaibeiras, considerando-se todas as árvores amostradas e apenas aquelas produtivas

Table 2 - Twenty-four hour production, in liters, of oil-resin for different types of Copaifera sp., mean production values were calculated considering all oil-producing individuals and also all sampled trees

\begin{tabular}{|c|c|c|c|c|c|c|}
\hline \multirow[t]{2}{*}{$\begin{array}{l}\text { Morfotipos } \\
\text { de Copaíba }\end{array}$} & \multirow[t]{2}{*}{ Média } & \multirow[t]{2}{*}{ Erro-padrão } & \multicolumn{2}{|c|}{$\begin{array}{l}\text { Intervalo de Confiança } \\
\text { de } 95 \% \text { para Média } \\
\end{array}$} & \multicolumn{2}{|c|}{ Amplitude } \\
\hline & & & Limite Inferior & Limite Superior & Mínimo & Máximo \\
\hline & \multicolumn{6}{|c|}{ Árvores Amostradas } \\
\hline Preta & 1,14 & 0,20 & 0,74 & 1,53 & 0 & 18,00 \\
\hline Amarela & 1,04 & 0,45 & 0,13 & 1,96 & 0 & 11,00 \\
\hline Mari-mari & 1,33 & 0,31 & 0,69 & 1,98 & 0 & 4,60 \\
\hline Branca & 0,48 & 0,20 & 0,06 & 0,90 & 0 & 4,50 \\
\hline Vermelha & 0,38 & 0,11 & 0,16 & 0,61 & 0 & 5,50 \\
\hline \multirow[t]{2}{*}{ Geral } & 0,94 & 0,13 & 0,69 & 1,19 & 0 & 18,00 \\
\hline & \multicolumn{6}{|c|}{ Árvores Produtivas } \\
\hline Preta & 3,84 & 0,55 & 2,74 & 4,93 & 0,10 & 18,00 \\
\hline Amarela & 3,47 & 1,17 & 0,77 & 6,17 & 0,05 & 11,00 \\
\hline Mari-mari & 1,64 & 0,35 & 0,90 & 2,38 & 0,07 & 4,60 \\
\hline Branca & 1,59 & 0,53 & 0,35 & 2,82 & 0,10 & 4,50 \\
\hline Vermelha & 1,57 & 0,35 & 0,83 & 2,31 & 0,05 & 5,50 \\
\hline Geral & 2,92 & 0,33 & 2,27 & 3,56 & 0,05 & 18,00 \\
\hline
\end{tabular}

Quadro 3 - Análise de variância do efeito do morfotipo na média da produção de óleo-resina em relação às árvores amostradas e árvores produtivas

Table 3 - Analysis of variance for morphotype effect on Copaifera sp. oil-resin production; mean production values were calculated considering all oil-producing individuals and also all sampled trees

\begin{tabular}{|c|c|c|c|c|}
\hline Fonte de variação & $\mathrm{GL}^{1}$ & $\mathrm{QM}^{2}$ & $\mathrm{~F}$ & $\operatorname{Sign}^{3}$ \\
\hline & \multicolumn{4}{|c|}{ Árvores Amostradas } \\
\hline Modelo & 9 & 50,052 & 8,352 & 0,000 \\
\hline Município & 1 & 7,179 & 1,198 & 0,274 \\
\hline Morfotipo & 4 & 12,725 & 2,123 & 0,077 \\
\hline Interação Município x Morfotipo & 3 & 18,939 & 3,160 & 0,025 \\
\hline Erro & 379 & 5,993 & & \\
\hline \multirow[t]{2}{*}{ Total } & 388 & & & \\
\hline & \multicolumn{4}{|c|}{ Árvores Produtivas } \\
\hline Modelo & 9 & 154,093 & 13,389 & 0,000 \\
\hline Município & 1 & 15,125 & 1,314 & 0,254 \\
\hline Morfotipo & 4 & 33,362 & 2,899 & 0,025 \\
\hline Interação Município x Morfotipo & 3 & 54,263 & 4,715 & 0,004 \\
\hline Erro & 116 & 11,508 & & \\
\hline Total & 125 & & & \\
\hline
\end{tabular}

${ }^{1}$ Grau de liberdade; ${ }^{2}$ Quadrado médio e ${ }^{3}$ Nível de significância pelo teste F.

R. Árvore, Viçosa-MG, v.30, n.4, p.583-591, 2006 
Quadro 4 - Comparação das médias de produção de óleo-resina por meio do teste t (GL = 120, assumindo-se igual variância entre os morfotipos)

Table 4-T-test comparison of mean values of Copaifera sp. oil-resin production ( $d f=120$; assuming equal variance within morphotypes)

\begin{tabular}{|c|c|c|c|c|c|c|c|c|}
\hline \multirow[b]{2}{*}{ Contrastes } & \multicolumn{5}{|c|}{ Morfotipos de Copaíba } & \multirow[b]{2}{*}{ Valor do Contraste } & \multirow[b]{2}{*}{$\mathrm{t}$} & \multirow[b]{2}{*}{$\operatorname{Sign}^{1}$} \\
\hline & Amarela & Branca & Mari-Mari & Preta & Vermelha & & & \\
\hline A & -4 & 1 & 1 & 1 & 1 & $-5,25$ & $-1,046$ & 0,298 \\
\hline B & 1 & -4 & 1 & 1 & 1 & 4,16 & 0,828 & 0,409 \\
\hline $\mathrm{C}$ & 1 & 1 & -4 & 1 & 1 & 3,92 & 1,094 & 0,276 \\
\hline $\mathrm{D}$ & 1 & 1 & 1 & -4 & 1 & $-7,08$ & $-2,659$ & 0,009 \\
\hline $\mathrm{E}$ & 1 & 1 & 1 & 1 & -4 & 4,26 & 1,131 & 0,260 \\
\hline
\end{tabular}

${ }^{1}$ Nível de significância para o contraste, pelo teste t.

Quadro 5 - Produção de óleo-resina em função do ambiente (baixio ou terra firme) e da tipologia florestal (floresta aberta ou floresta densa)

Table 5 - Copaifera sp. oil-resin production as a function of environment (seasonally flooded or terra firme) and forest type (open or dense)

\begin{tabular}{|c|c|c|c|c|c|c|c|c|}
\hline \multirow[b]{2}{*}{ Característica } & \multicolumn{4}{|c|}{ Árvores Amostradas } & \multicolumn{4}{|c|}{ Árvores Produtivas } \\
\hline & $\mathrm{n}$ & Média & $\begin{array}{c}\text { Erro-Padrão } \\
\text { da Média }\end{array}$ & $\mathrm{P}$ & $\mathrm{n}$ & Média & $\begin{array}{l}\text { Erro-Padrão } \\
\text { da Média }\end{array}$ & $\mathrm{P}$ \\
\hline Baixio & 78 & 1,03 & 0,31 & 0,719 & 32 & 2,51 & 0,67 & 0,469 \\
\hline Terra Firme & 310 & 0,92 & 0,14 & & 93 & 3,06 & 0,38 & \\
\hline Floresta Aberta & 63 & 1,04 & 0,34 & 0,736 & 28 & 2,33 & 0,69 & 0,339 \\
\hline Floresta Densa & 325 & 0,92 & 0,14 & & 97 & 3,09 & 0,37 & \\
\hline Tarauacá & 115 & 0,92 & 0,22 & 0,936 & 46 & 2,31 & 0,49 & 0,158 \\
\hline Xapuri & 273 & 0,95 & 0,15 & & 79 & 3,27 & 0,43 & \\
\hline
\end{tabular}

Quadro 6 - Produção de óleo-resina, em L árvore ${ }^{-1}$, em relação à classe de diâmetro de árvores de copaíba, considerandose todas as árvores amostradas ou apenas as árvores produtivas

Table 6-Copaifera sp. Oil-resin production in liters/tree based on diameter class; mean production values were calculated considering all oil-producing individuals and also all sampled trees

\begin{tabular}{|c|c|c|c|}
\hline \multirow[t]{2}{*}{ Classe de DAP } & \multirow[t]{2}{*}{ Limites da Classe } & \multicolumn{2}{|c|}{ Produção de Óleo-Resina (L árvore ${ }^{-1}$ ) } \\
\hline & & Todas as Árvores & Árvores Produtivas \\
\hline 1 & $36 \leq \mathrm{DAP}<46$ & 0,83 & \\
\hline 2 & $46 \leq \mathrm{DAP}<56$ & 0,38 & 0,63 \\
\hline 3 & $56 \leq \mathrm{DAP}<66$ & 1,30 & 3,24 \\
\hline 4 & $66 \leq \mathrm{DAP}<76$ & 0,67 & 2,47 \\
\hline 5 & $76 \leq \mathrm{DAP}<86$ & 0,75 & 2,06 \\
\hline 6 & $86 \leq \mathrm{DAP}<96$ & 0,87 & 2,38 \\
\hline 7 & $96 \leq \mathrm{DAP}<106$ & 1,92 & 3,94 \\
\hline 8 & $106 \leq \mathrm{DAP}<116$ & 0,87 & 3,06 \\
\hline 9 & $116 \leq \mathrm{DAP}<126$ & 0,96 & 3,49 \\
\hline 10 & $126 \leq \mathrm{DAP}<136$ & 1,47 & 5,03 \\
\hline 11 & $136 \leq \mathrm{DAP}<146$ & 0,61 & 2,74 \\
\hline 12 & $146 \leq \mathrm{DAP}<156$ & 0,13 & 1,14 \\
\hline 13 & $156 \leq \mathrm{DAP}<166$ & 0,62 & 2,07 \\
\hline 14 & $166 \leq \mathrm{DAP}<186$ & 0,30 & \\
\hline
\end{tabular}

As análises de variâncias da regressão linear e quadrática de cada morfotipo para a produção de óleoresina em relação às classes de diâmetro não foram significativas (Quadro 7), embora tenha sido observado grande variação nas classes de diâmetro (Quadro 6). Esses resultados concordam com os obtidos por Alencar et al. (1982), que não encontram diferenças significativas na correlação entre o diâmetro do fuste e altura e diâmetro 
da copa das árvores e a produção do óleo-resina, embora esses autores tenham observado ligeira tendência de as árvores com valores extremos para DAP (as de menor e maior classe de diâmetro) apresentarem menor produtividade. O elevado valor para o nível de significância (sempre maior que $37 \%$ ) indica que, mesmo o modelo com melhor ajuste, não pode ser usado para predizer a produção das copaíbas com base no DAP das árvores.

Plowden (2001) relatou que árvores com diâmetro entre 55 e $65 \mathrm{~cm}$ apresentam maior produção média que as árvores com diâmetro maior ou menor que os limites estabelecidos. Isso indica que a produção aumentaria com o crescimento da árvore até um limite máximo e a partir desse ponto houvesse novamente diminuição na produção, ajustando-se a um modelo não-linear.
Entretanto, somente nos morfotipos mari-mari e vermelha o modelo quadrático ajustou-se melhor que o linear, porém nenhum dos modelos demonstrou qualquer relação entre a classe de diâmetro e a produção de óleo-resina.

Quadro 7 - Modelos de regressão da relação entre a produção de óleo-resina de árvores de copaíba (P, em L árvore $^{-1}$ ) e a classe de diâmetro de cada um dos morfotipos (C), em cm

Table 7-Regression models of the relationship between Copaifera sp. oil-resin production ( $P$, liters/tree) and diameter class of each morphotype $(C)$ in centimeters

\begin{tabular}{llcc}
\hline $\begin{array}{l}\text { Morfotipo } \\
\text { de Copaíba }\end{array}$ & \multicolumn{1}{c}{ Modelo de Regressão } & $\mathrm{R}^{2}$ & $\alpha$ \\
\hline Amarela & $\mathrm{P}=1,17+0,37 \mathrm{C}$ & 0,05 & 0,54 \\
Branca & $\mathrm{P}=1,38+0,03 \mathrm{C}$ & 0,00 & 0,93 \\
Mari-mari & $\mathrm{P}=4,49-1,97 \mathrm{C}+0,28 \mathrm{C}^{2}$ & 0,10 & 0,37 \\
Preta & $\mathrm{P}=4,70-0,11 \mathrm{C}$ & 0,00 & 0,63 \\
Vermelha & $\mathrm{P}=5,92-1,02 \mathrm{C}+0,05 \mathrm{C}^{2}$ & 0,10 & 0,39 \\
\hline
\end{tabular}
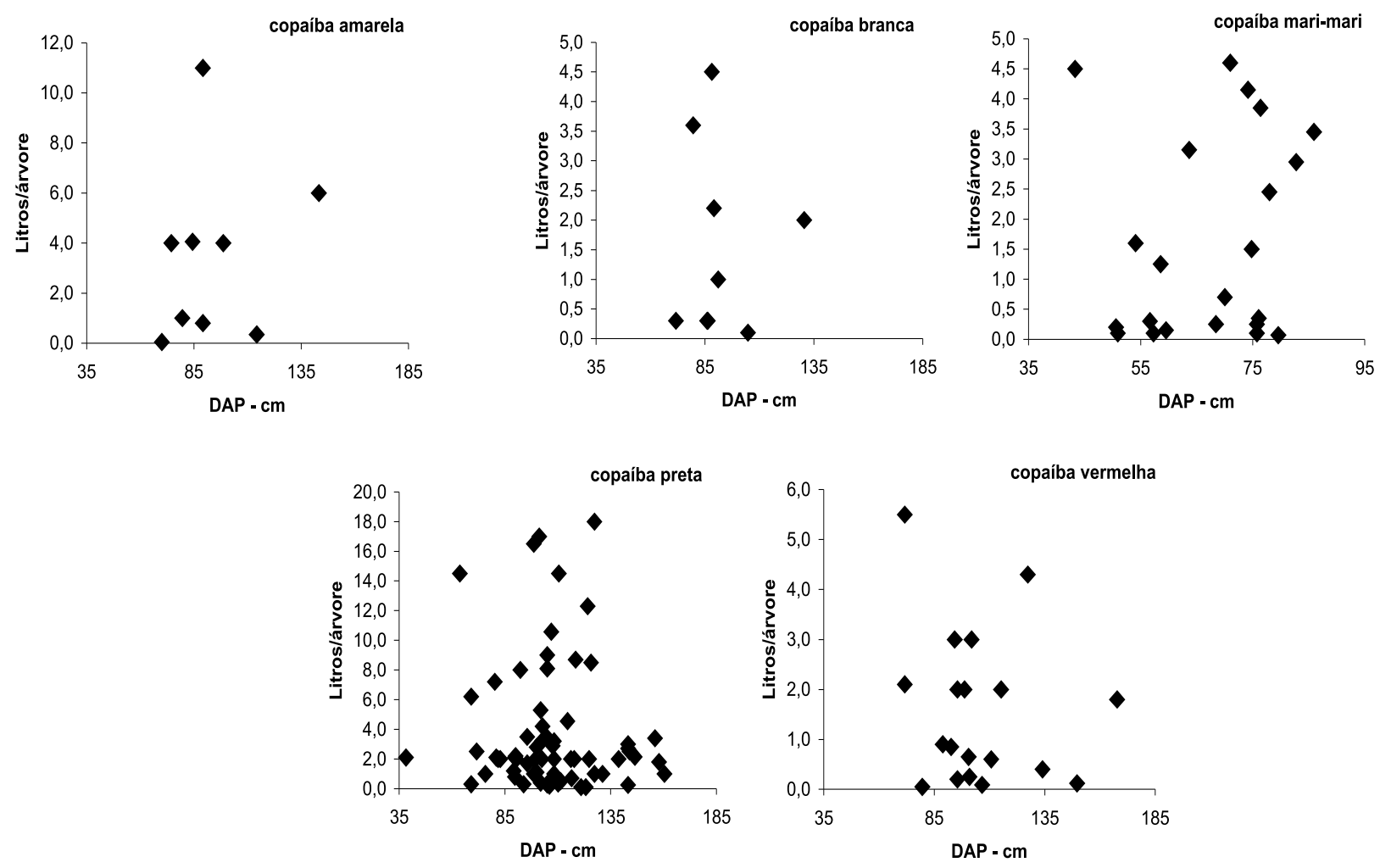

Figura 1 - Produção de óleo-resina de morfotipos de copaíba em função do DAP das árvores. Figure 1 -Scatter plot of oil-resin production and diameter of Copaifera spp. morphotypes. 


\section{CONCLUSÕES}

A produção de óleo-resina de copaíba foi independente do ambiente (terra firme ou baixio) ou da tipologia florestal, porém dependente do morfotipo de copaíba. O tamanho da árvore, avaliado pelo diâmetro à altura do peito, não influenciou a produção de óleoresina das copaibeiras.

A copaíba-preta apresentou elevada proporção de árvores não-produtivas, no entanto, considerando apenas as árvores produtivas, foi o morfotipo que exibiu a maior produção média de óleo-resina por árvore. A copaíba mari-mari foi a que teve a maior proporção de árvores produtivas.

De maneira geral, a copaíba-preta e a mari-mari foram as que apresentaram maior potencial para a produção de óleo-resina, no entanto, para que o manejo da copaíba seja viável e cumpra com seu papel para a conservação das florestas e manutenção da tradição extrativista das populações locais, é necessário um sistema de uso múltiplo da floresta. A copaíba é uma espécie com enorme diversidade (fisiológica e morfológica), e ainda há vários fatores desconhecidos que precisam ser estudados.

\section{AGRADECIMENTOS}

À Christie Klimas, da Universidade da Flórida, pela revisão dos originais; à Nívea Maria de Paula Fernandes, da Universidade Federal do Acre, pelas sugestões; à Fundação Ford e ao Ministério do Meio Ambiente, pelo apoio financeiro.

\section{REFERÊNCIAS BIBLIOGRÁFICAS}

ACRE. Secretaria de Estado de Planejamento Coordenação. Zoneamento EcológicoEconômico: indicativos para a gestão territorial do Acre. Rio Branco: 2000. v. 1.

ALENCAR, J. C. Estudos silviculturais de uma população natural de Copaifera multijuga HAYNE - LEGUMINOSASEAE, na Amazônia Central. 2 Produção de óleo-resina. Acta Amazônica. v. 12, n. 1, p. 79-82, 1982.
CASCON, V.; GILBERT, B. Characterization of the chemical composition of oleoresins of Copaifera guianensis Desf., Copaifera duckei Dwyer and Copaifera multijuga Hayne. Phytochemistry, v. 55 , p. $773-778,2000$.

DWYER, J. D. The Central American, West Indian and South American species of Copaifera (Caesalpiniaceae). Brittonia, v. 7, n. 3, p. 143-172, 1951.

FERREIRA, L. A. Potencial de extração e comercialização do óleo-resina de copaíba (Copaifera spp.): um estudo de caso na Floresta Estadual do Antimary, Acre. 1999. 54f. Dissertação (Mestrado em Ecologia e Manejo de Recursos Naturais) - Universidade Federal do Acre, Rio Branco, 1999.

LEITE, A. et al. Recomendações para o manejo sustentável do óleo de copaíba. Rio Branco: Universidade Federal do Acre, 2001. 38 p.

PLOWDEN, C. The ecology, management and marketing of non-timber forest products in the Alto Rio Guamá indigenous reserve (eastern Brazilian Amazon). 2001. (Ph.D. in Ecology) - Penn State University, University Park, 2001.

PLOWDEN, C. Production ecology of copaíba (Copaifera spp) Oleoresin in the Eastern brazilian Amazon. Economic Botany, v. 57, n. 4, p. 491-501, 2003.

SAMPAIO, P.T.B. Copaíba. In: CLAY, W; SAMPAIO,P.T.; CLEMENT, C.R.

Biodiversidade amazônica: exemplos e estratégias de utilização, por Manaus : [INPA], 2000. p. 207-215, 2000.

VEIGA JUNIOR, F.; PINTO, A.C. O Gênero Copaifera L. Química Nova, v. 25, n. 2, p. 273-286, 2002. 